\title{
Bidirectional Text Messaging to Improve Adherence to Recommended Lipid Testing
}

\author{
Laura-Mae Baldwin, MD, MPH, Caitlin Morrison, MPH, Jonathan Griffin, MD, MHA, \\ Nick Anderson, PhD, Kelly Edwards, PhD, MA, Jeff Green, BS, Cleary Waldren, MS, \\ and William Reiter, MD, FACP
}

Background: Synergies between technology and health care in the United States are accelerating, increasing opportunities to leverage these technologies to improve patient care.

Methods: This study was a collaboration between an academic study team, a rural primary care clinic, and a local nonprofit informatics company developing tools to improve patient care through population management. Our team created a text messaging management tool, then developed methods for and tested the feasibility of bidirectional text messaging to remind eligible patients about the need for lipid testing. We measured patient response to the text messages, then interviewed 8 patients to explore their text messaging experience.

Results: Of the 129 patients the clinic was able to contact by phone, $29.4 \%$ had no cell phone or textmessaging capabilities. An additional 20\% refused to participate. Two thirds of the 28 patients who participated in the text messaging intervention (67.9\%) responded to at least 1 of the up to 3 messages. Seven of 8 interviewed patients had a positive text-messaging experience.

Conclusions: Bidirectional text messaging is a feasible and largely acceptable form of communication for test reminders that has the potential to reach large numbers of patients in clinical care. ( $\mathrm{J}$ Am Board Fam Med 2017;30:608-614.)

Keywords: Adherence, Health Information Technology, Patient Engagement, Quality Improvement, Rural Health

Synergy between technology and health care in the United States is accelerating. The proportion of office-based physicians using certified electronic health records (EHRs) was $77.9 \%$ in $2015 .^{1}$ EHRs have created opportunities to identify patients with health

\footnotetext{
This article was externally peer reviewed.

Submitted 28 February 2017; revised 22 May 2017; accepted 31 May 2017.

From the Department of Family Medicine, University of Washington, Seattle, WA (LMB); Kaiser Permanente Washington Health Research Institute, Seattle (CM); Blue Cross and Blue Shield of IL, MT, NM, OK, TX (JG); Department of Public Health Sciences, University of California-Davis, Davis, CA (NA); Department of Bioethics and Humanities, University of Washington, Seattle (KE); Prognosis Data, LLC, Guilford, CT (JG); St. Lukes Health System, Boise, ID (CW); Northwest EHR Collaborative, Anaconda, MT (WR).

Funding: This research was funded by the Office of the National Coordinator for Health Information Technology under award number 10775336, the Northwest EHR Collaborative, and the National Center for Advancing Translational Sciences of the National Institutes of Health under Award Number UL1TR000423. The content is solely the responsibility of the authors and does not necessarily represent the official views of the Office of the National Coordi
}

care gaps, and to monitor health care in new ways, especially since patients are simultaneously adopting personal technologies with communication and health applications.

Roughly $92 \%$ of adults own cellular phones, ${ }^{2}$ and $80 \%$ of cellular phone owners use text messaging. ${ }^{3}$ Patients seem willing to provide health information via text messaging, although this has been best studied in chronic illness management. ${ }^{4-9}$ Systematic reviews examining mobile phone messaging reminders for health care in general,${ }^{10}$ for attendance at health care appointments, ${ }^{11}$ for facilitating self management of longterm illnesses, ${ }^{12}$ and for promoting preventive health care, ${ }^{13,14}$ have suggested benefits, but scarce literature exists about bidirectional text

nator for Health Information Technology or the National Institutes of Health.

Conflict of interest: none declared.

Corresponding author: Laura-Mae Baldwin, MD, MPH, University of Washington, Department of Family Medicine, Box 354696, Seattle, WA 98195-4696 (E-mail lmb@uw.edu). 
messaging to improve testing adherence, especially in rural areas.

This project assessed the feasibility and patient experience of using 2-way text messaging to improve adherence to recommended lipid testing.

\section{Methods}

\section{Design}

This mixed-methods study developed methods for and tested the feasibility of bidirectional text messaging within a primary care clinic, then interviewed patients to explore their text messaging experience. The University of Washington Human Subjects Division and the Ethics and Corporate Compliance Committee of the project's clinical partner approved the study.

\section{Setting}

The study clinic, located in a rural Montana city, had 2 participating family physicians. The collaborating practice helped develop the text messaging intervention. One of the clinic's family physicians chose the testing topic-lipid testing for high-risk conditions (diabetes mellitus, ischemic vascular disease, coronary artery disease, or hyperlipidemia).

\section{Text Messaging Infrastructure}

The clinic had a Business Associate Agreement with Northwest EHR Collaborative (NWEHR), a Montana-based nonprofit informatics company developing tools to improve clinics' management of the health of their patient populations. NWEHR developed a system to conduct and track the text messaging intervention $^{15}$ that included a Research Electronic Data Capture (REDCap) study management component, ${ }^{16}$ a text messaging gateway using the commercial third-party Twilio system, and an intermediary message brokerage system that queried, delivered, and monitored messages between Twilio and REDCap. The study management system was accessible only to agents of NWEHR. It received a baseline data feed of patient status, then monthly updated data feeds to identify eligible patients when the text messages were scheduled. Messages to patients were limited to the standard SMS 160-character limit. Message responses from patients were monitored by staff. At the trial's conclusion, data were deidentified and exported to the researchers.

\section{Identification of Eligible Patients}

The clinic's information technology staff used EHR data to identify all the study physicians' patients ages 18 to 75 years with at least 1 face-to-face visit with a medical provider in the practice in the previous 12 months, and who needed a low-density lipoprotein cholesterol (LDL) test based on recommendations at the time of the study.

\section{Patient Text Messaging Capabilities and Willingness}

Clinic representatives attempted to call the 248 eligible patients and notify them that their primary care physician was participating in a project sending text messages to patients to remind them about cholesterol testing. Of the 248 eligible patients (Figure 1), 112 were not reached after 3 calls, and 7 of those reached were no longer clinic patients. Of the remaining 129, 29 (29.4\%) either had no cell phone or no text messaging, and 26 (20.2\%) refused participation. The clinic representative verified the cellular phone number of the 65 willing and eligible individuals. These 65 individuals were more likely to be privately insured $(67.7 \%$ vs $53.6 \% ; P=.048)$ and under 55 years $(47.7 \%$ vs $33.9 \% ; P=.048)$ than the 183 who were not. Four of the 65 had LDL testing in the roughly 4 weeks before the text message program launch, and were excluded. The 61 patients were randomly assigned to receive the text messages $(\mathrm{n}=31)$ or not $(\mathrm{n}=$ 30) as part of a feasibility clinical trial (not reported here). After the first text message, 1 individual asked to no longer receive text messages; 2 couples (both members of the couples were in the study) had duplicate cellular phone numbers; and 1 patient was mistakenly assigned a duplicate wrong cellular phone number.

\section{Text Messaging Intervention}

The intervention involved 3 text messages 4 weeks apart, reminding individuals to come to the clinic laboratory: "You are due for a cholesterol test. Reply 1 for YES, I will go to < clinic name's $>$ lab this week, open 7:30 to $6 \mathrm{M}-\mathrm{F}$. Reply 2 for NO. Fasting not needed." Patients who came for LDL testing received no further text messages. The study team measured patient response within 48 hours to each text message. 
Figure 1. Patient identification and recruitment flow diagram.

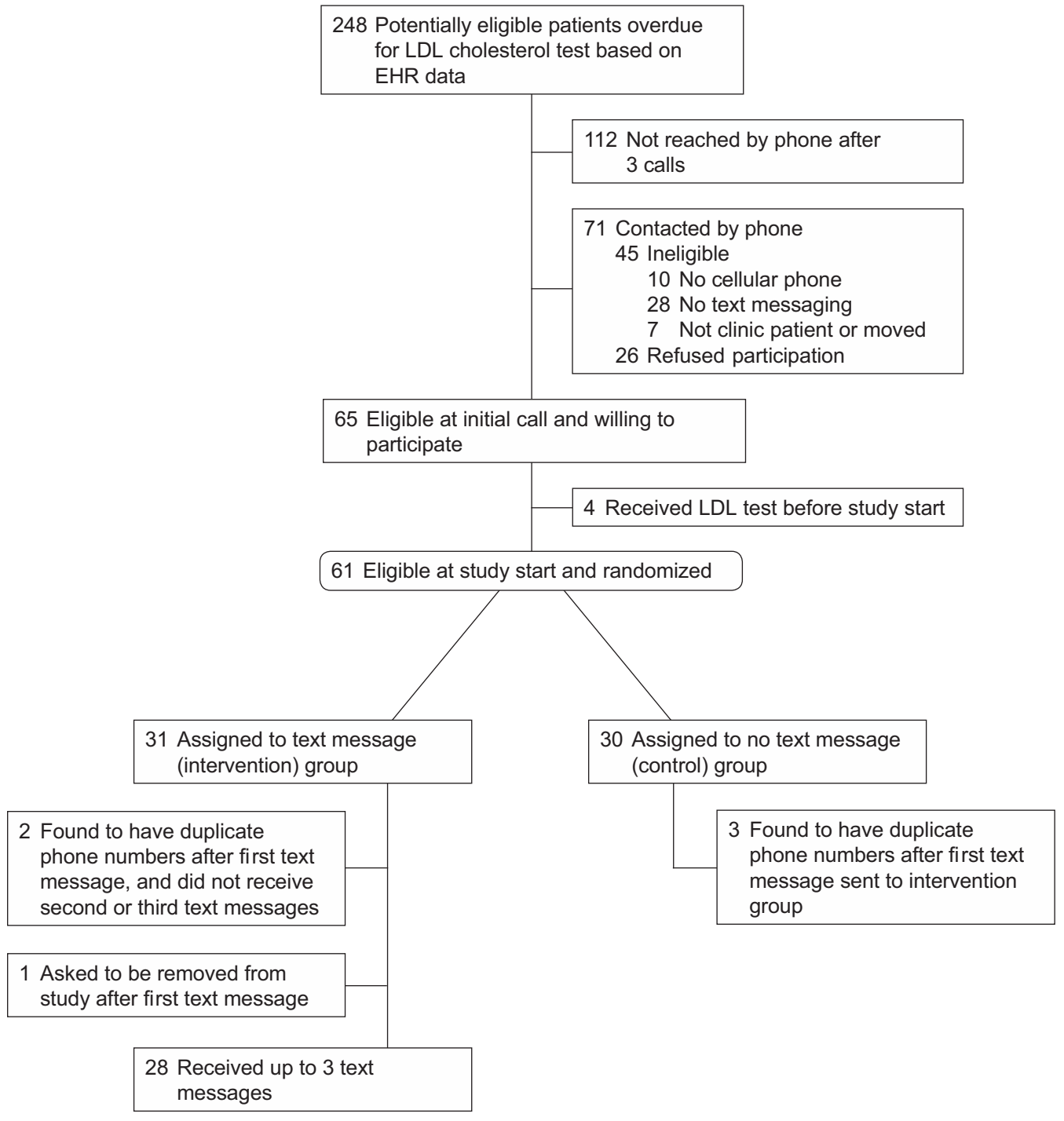

\section{Patient Interviews}

One week after the second text message reminder, all 28 text messaging group members received a text message invitation: " $<$ Clinic name $>$ wants your ideas about its text message system. Reply 1 for YES, call me for a 10 minutes research interview (\$10 paid for interview). Reply 2 for NO." Three persons responded; 2 agreed to participate. A clinic physician called the remaining 25 individuals; 9 agreed to participate. Eight of the 11 who agreed completed the interview. An interview guide combined closed- and open-ended questions to assess patient experiences with the text message reminders (Appendix).

A University of Washington research scientist conducted the telephone interviews, document- ing with handwritten notes. Frequencies of closed-ended responses were calculated, and 2 research team members (CM, LMB) conducted a simple descriptive content analysis of openended responses.

\section{Results}

Two thirds of the text messaging group (19/28, $67.9 \%$ ) responded to at least 1 of the up to 3 text messages. In the first month, $53.6 \%$ of the 28 patients responded by text (Table 1). This decreased to roughly a third of patients in the second and third months. Patients who responded usually answered yes or no, as requested. In a few cases, the respondents' text message tried to communicate 
Table 1. Text Message Responses by Month Message Was Sent

\begin{tabular}{lc}
\hline Response Type & Percent with Response Type \\
\hline Month 1 & $\mathrm{~N}=15 / 28^{*}$ sent text message \\
Yes & 40.0 \\
No & 40.0 \\
$\quad$ Other response ("Who is this for?" "I already had the above text done & 20.0 \\
$\quad$ prior to seeing Dr. XXXXX in early March of this year." “.”) & $7 / 21$ sent text message \\
Month 2 & 42.9 \\
Yes & 28.6 \\
No & 28.6 \\
Other response ("I also need to get a PSA test for [another provider]. & $\mathrm{N}=6 / 16$ sent text message \\
I will wait and coordinate into one lab visit." "Already had one!") & 16.7 \\
Month 3 & 83.3 \\
Yes & 0.0 \\
No & $\mathrm{N}$ \\
Other response & \\
\hline
\end{tabular}

* Three intervention group patients were excluded from this table: 1 who asked to receive no further text messages, and 2 with duplicate numbers identified after the first text message.

other information to their physician (eg, "I also need to get a PSA test. . ").

Of the 8 interview respondents, 5 were 55 or older; 4 were employed, 3 retired, 1 a homemaker. All 8 had attended some college; all had insurance. Seven had a positive experience with the text messages, even though only half preferred text messaging as a communication method. Five did not come in for LDL testing (Table 2); of these, 4 did not think they were due for the test. Six had concerns about maintaining personal health information privacy in text messages.

\section{Discussion}

Most individuals participating in the text message program responded to the messages and sent interpretable responses, consistent with results in other literature. ${ }^{5,17,18}$ Because text messaging is a powerful communication tool, it is not surprising that several patients communicated information beyond that requested. Because clinics may have limited staff to respond to patient text messages, clinics adopting a text-based intervention must be clear about what return communications patients can expect, if any.

In this study, clinic representatives first called patients to ascertain their willingness to receive text messages, and to verify their cellular phone numbers. Many patients were not reached, possibly because the calls were not always made by a clinic representative known to the patient. To succeed in clinical practice, approval for text message reminders would best be integrated into clinic workflow (eg, at registration). Since nearly half of the patients reached agreed to receive text messages, text message reminders could reach a significant proportion of a clinic's patient population.

This study's interviews suggested that text messaging is an acceptable form of communication between consenting patients and clinics. However, most patients expressed concerns about health information privacy. Literature in this area is sparse, ${ }^{19}$ and learning more about what patients are comfortable sending and receiving by text messaging is important. Some patients preferred other modes of communication, consistent with literature that has given patients a choice of remote communication methods. ${ }^{19-23}$ Thus, clinics may wish to ask patients about their preferred communication methods, and offer multiple options to provide patient-centered communications.

This feasibility study recruited from the practices of only 2 physicians, limiting its generalizability. The small number of interviews limits the reliability of these findings. We were unable to determine whether individuals received tests at locations other than the participating clinic. Because elders use cellular phones and texting less often, we only included adults under 75 years.

Implementing clinical care guidelines is challenging, especially in rural settings where many patients travel longer distances for care. ${ }^{24}$ Only 


\begin{tabular}{|c|c|c|}
\hline & Percentage $(\mathrm{N}=8)$ & Quotation Examples \\
\hline $\begin{array}{l}\text { Remembered receiving the text } \\
\text { message }\end{array}$ & 100.0 & \\
\hline \multicolumn{3}{|l|}{ Experience of text message } \\
\hline \multirow[t]{4}{*}{ Positive } & 87.5 & $\begin{array}{l}\text { "Yes. I think it's a good idea, people make appointments and } \\
\text { it helps to recall when to do." }\end{array}$ \\
\hline & & "... it was positive and convenient." \\
\hline & & $\begin{array}{l}\text { ". . I liked it. Text is an easy way to communicate and can } \\
\text { also be automated." }\end{array}$ \\
\hline & & "Overall once you get the kinks out this could be great." \\
\hline Did not understand text message & 12.5 & $\begin{array}{l}\text { "When I got the message I had no idea what was going on. } \\
\text { It appeared on my screen and then disappeared. I didn't } \\
\text { know how to go back in and retrieve it ... thought it } \\
\text { might have been for something else." }\end{array}$ \\
\hline \multicolumn{3}{|l|}{ Received LDL testing during study } \\
\hline Yes & 37.5 & $\begin{array}{l}\text { ". . responded to the first one saying that I would come in } \\
\text { but forgot, so the follow-up reminder was a good thing." }\end{array}$ \\
\hline \multirow[t]{2}{*}{ No } & 62.5 & $\begin{array}{l}\text { "I didn't respond because I also have a doc in Missoula and I } \\
\text { will just call and come in when I can. It would be helpful } \\
\text { if there are extenuating circumstances, like mine, to } \\
\text { include a phone number." }\end{array}$ \\
\hline & & $\begin{array}{l}\text { "I already had a cholesterol test. I thought they were the } \\
\text { same test because the instructions said no fasting, so I } \\
\text { didn't think I needed to get that." }\end{array}$ \\
\hline
\end{tabular}

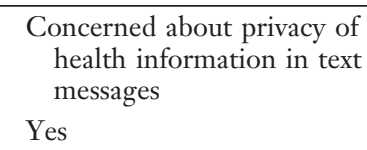

No

Don't know

Preferred communication method for health reminders

Texting only

Text and other

25.0

Other method preferred
"It depends on what the information is."

"A cholesterol test $<$ reminder $>$ is not confidential, but confidential information should not be texted."

"Very concerned. Same with health records going online, knowing that everything is out there."

"Not that concerned."

"Not being a real techie I don't really know about text messages and their ability to be intercepted."

"Email $<$ I $>$ would treat like spam. Postal mail $<$ I $>$ don't look at. For right now text messages are the most notable."

"Text $<$ is $>$ most readily identifiable. Get it right away. Emails will go days without getting answered."

"Anything that involves less paper and envelopes."

“... text could interrupt what I am doing. So I would say email."

"I like postal. Text stays out there forever, < postal mail $>$ is private." about half of adult and pediatric patients nationally receive indicated care. ${ }^{25,26}$ This feasibility study suggests that text messaging is a viable and largely acceptable form of communication for test reminders. The study team worked collaboratively with a community-based practice to develop a sustainable, generalizable reminder system that can function efficiently in a small to medium-sized clinic serving a rural population. A full-scale ran- domized clinical trial is needed to study implementation of workflow processes that identify patients willing to receive text message reminders, and to examine and compare the impact and cost effectiveness of sending reminders in different doses on medical monitoring such as laboratory tests.

The authors thank Chris Miller for his work in identifying eligible patients and providing baseline data and monthly up- 
dates from electronic health records; Brenda Benefiet, Mitchell Marrujo, and Anthony Beaver for contacting patients regarding their willingness to be part of this text messaging program; and Lalitha Ramesh for helping develop the data capture and management system.

To see this article online, please go to: http://jabfm.org/content/ 30/5/608.full.

\section{References}

1. Health IT.gov. Office-based physician electronic health record adoption 2015. Available from: https:// dashboard.healthit.gov/quickstats/pages/physicianehr-adoption-trends.php. Accessed May 12, 2017.

2. Anderson M. Technology device ownership: 2015. Available from: http://www.pewinternet.org/2015/ 10/29/technology-device-ownership-2015. Accessed May 12, 2017.

3. Duggan M, Rainie L. Cell phone activities 2012. November 25, 2012. Washington, DC: Pew Internet, 2012; 20.

4. Anhoj J, Moldrup C. Feasibility of collecting diary data from asthma patients through mobile phones and SMS (short message service): Response rate analysis and focus group evaluation from a pilot study. J Med Internet Res 2004;6(4):e42.

5. Smith B, Harms WD, Burres S, et al. Enhancing behavioral health treatment and crisis management through mobile ecological momentary assessment and SMS messaging. Health Informatics J 2012;18: 294-308.

6. Lee SS, Xin X, Lee WP, et al. The feasibility of using SMS as a health survey tool: An exploratory study in patients with rheumatoid arthritis. Int J Med Inform 2013;82:427-34.

7. Mbuagbaw L, Thabane L, Ongolo-Zogo P. Opening communication channels with people living with $\mathrm{HIV}$ using mobile phone text messaging: Insights from the CAMPS trial. BMC Res Notes 2013;6:131.

8. Macedo LG, Maher CG, Latimer J, et al. Feasibility of using short message service to collect pain outcomes in a low back pain clinical trial. Spine (Phila Pa 1976) 2012;37:1151-5.

9. Christie A, Dagfinrud H, Dale O, et al. Collection of patient-reported outcomes-Text messages on mobile phones provide valid scores and high response rates. BMC Med Res Methodol 2014;14:52.

10. Kannisto KA, Koivunen MH, Valimaki MA. Use of mobile phone text message reminders in health care services: A narrative literature review. J Med Internet Res 2014;16(10):e222.

11. Gurol-Urganci I, de Jongh T, Vodopivec-Jamsek V, et al. Mobile phone messaging reminders for attendance at healthcare appointments. Cochrane Database Syst Rev 2013(12):CD007458.

12. de Jongh T, Gurol-Urganci I, Vodopivec-Jamsek V, et al. Mobile phone messaging for facilitating selfmanagement of long-term illnesses. Cochrane Database Syst Rev 2012;12:CD007459.
13. Vodopivec-Jamsek V, de Jongh T, Gurol-Urganci I, et al. Mobile phone messaging for preventive health care. Cochrane Database Syst Rev 2012;12: CD007457.

14. Smith C, Gold J, Ngo TD, et al. Mobile phonebased interventions for improving contraception use. Cochrane Database Syst Rev 2015(6):CD011159.

15. Anderson N, Morrison C, Griffin J, et al. Governance strategies for conducting text messaging interventions in clinical research. Clin Transl Sci 2014;7: 127-31.

16. Harris PA, Taylor R, Thielke R, et al. Research electronic data capture (REDCap) - A metadatadriven methodology and workflow process for providing translational research informatics support. J Biomed Informatics 2009;42:377-81.

17. Brannan SO, Dewar C, Taggerty L, et al. The effect of short messaging service text on non-attendance in a general ophthalmology clinic. Scott Med J 2011; 56:148-50.

18. Ingersoll K, Dillingham R, Reynolds G, et al. Development of a personalized bidirectional text messaging tool for HIV adherence assessment and intervention among substance abusers. J Subst Abuse Treat. 2014;46:66-73.

19. Baptist AP, Thompson M, Grossman KS, et al. Social media, text messaging, and email-Preferences of asthma patients between 12 and 40 years old. J Asthma 2011;48:824-30.

20. Diamantidis CJ, Zuckerman M, Fink W, et al. Usability testing and acceptance of an electronic medication inquiry system for CKD patients. Am J Kidney Dis 2013;61:644-6.

21. Finkelstein SR, Liu N, Jani B, et al. Appointment reminder systems and patient preferences: Patient technology usage and familiarity with other service providers as predictive variables. Health Informatics J 2013;19:79-90.

22. Greaney ML, Puleo E, Sprunck-Harrild K, et al. Electronic reminders for cancer prevention: Factors associated with preference for automated voice reminders or text messages. Prev Med 2012;55:151-4.

23. Kratzke C, Wilson S, Vilchis H. Reaching rural women: Breast cancer prevention information seeking behaviors and interest in Internet, cell phone, and text use. J Community Health 2013;38:54-61.

24. Chan L, Hart LG, Goodman DC. Geographic access to health care for rural Medicare beneficiaries. J Rural Health 2006;22:140-6.

25. Mangione-Smith R, DeCristofaro AH, Setodji CM, et al. The quality of ambulatory care delivered to children in the United States. N Engl J Med 2007; 357:1515-23.

26. McGlynn EA, Asch SM, Adams J, et al. The quality of health care delivered to adults in the United States. N Engl J Med 2003;348:2635-45. 


\section{Appendix}

Improving Clinical Preventive Care Using Bidirectional Text Messaging: Interview Guide

$<$ Clinic Name $>$ is trying to find ways that help people get the health care they need.

$\mathrm{XX}$ weeks ago, $<$ Clinic Name $>$ sent you a text message with a reminder to get a cholesterol test.

1. Do you remember getting this text message? YES NO

IF YES:

1a. What did you think about getting a reminder like this via text message?

1.a.i. Follow-up questions:

Why was it a positive experience for you?

Why was it a negative experience for you?

If the person does not indicate the type of experience:

Was it a positive or negative experience for you? Depending on the answer, go back to 1.a.i.

1.a.ii. Did you get the cholesterol test? YES NO

If NO, why not?

If NO:

1.b. Have you gone in for a cholesterol test in the last XX weeks? YES NO

If YES, what prompted you to get it?

1.c. What do you think about using text messaging to get a reminder from $<$ Clinic Name $>$ for a cholesterol test?

1.c.i. Follow-up questions:

Why would it be a positive experience for you?

Why would it be a negative experience for you?

If the person does not indicate the type of experience:

Would it be a positive or negative experience for you? Depending on the answer, go back to 1.c.i.

2. There are many ways to get health reminders like this: phone, text message, postal mail, e-mail.
What do you think about getting a health reminder via text message compared with these other ways?

Prompt: Why do they think what they think?

3. How concerned are you, if at all, about the privacy of your health information in SMS messages?

To help us understand the answers we get in this study, we'd like to understand a few things about you:

4. What is your age?

5. Currently, are you working at a job? YES NO

If YES, how much time?

a. Full time

b. Part time

c. Not employed

d. Retired

e. Homemaker

f. A student

g. Refused

6. What is the last grade of school you have completed?
a. Eighth grade or less
b. Some high school
c. Graduated high school
d. Some college/associates degree
e. Graduated college
f. Post graduate
g. Refused

7. What type of insurance do you have?

Types would be:
a. Private Insurance
b. CHAMPUS (military insurance)
c. Medicare
d. Medicaid
e. No insurance
f. Other: 